\title{
Working in a post Covid-19 world: Towards a conceptual framework for distributed work
}

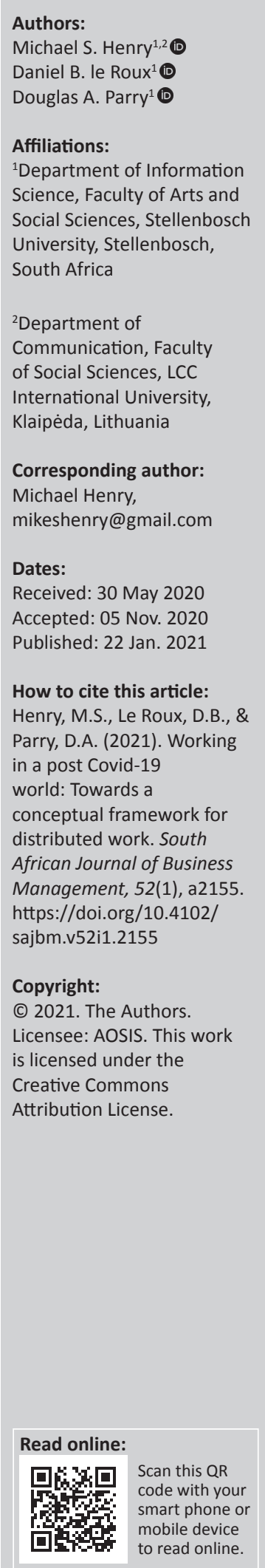

Purpose: Against the backdrop of the increased prevalence of telework practices as a result of Covid-19, the purpose of the present article is to address the conceptual confusion, overlap and ambiguity characterising much of the published literature in this domain through the development of an integrated conceptual framework describing distributed work practices at various levels of organisations.

Design/methodology/approach: To develop the framework, a collection of definitions for distributed work concepts were systematically selected and reviewed. These concepts include telework, remote work, distributed work and virtual work, as well as telecommuting, virtual teams, virtual organisations and distributed organisations. The reviewed definitions were systematically analysed to elicit the key principles underlying each concept, and then integrated to produce the conceptual framework.

Findings: Our analysis suggests that virtuality and distributedness can be defined as distinct continua which, when combined, can be used to describe particular work settings. Additionally, we identify four factors which impact organisational policy in terms of virtuality and distributedness: interdependence of tasks, nature of work, technological environment and temporal distance.

Practical implications: The framework offers managers a foundation for establishing distributed work policies and determining policy implications. Additionally, researchers conducting empirical investigations of distributed work practices can utilise the framework to differentiate between and describe particular work settings.

Originality/value: The conceptual integration of virtuality, distributedness and organisational levels present a novel and important development. As organisations adapt to the effects of the Covid-19 pandemic, the framework we propose serves as a useful artefact to support and inform their decision making.

Keywords: virtual work; remote work; distributed work; telecommute; virtual team; distributed organisation; virtuality; distributedness.

\section{Introduction}

The rapid spread of the Covid-19 disease in early 2020 triggered the implementation of a range of mobility-restriction policies (laws and regulations) in many parts of the world. These restrictions have had important and diverse impacts on the operations of organisations across sectors. Central amongst these has been the sudden emergence of the need to ensure, where possible, the continuity of business operations whilst employees who generally work from a central location (e.g., office, warehouse or factory) become geographically distributed (Mullenweg, 2020). Whilst concepts (and practices) like distributed work, telework and virtual work are by no means new phenomena, Covid-19 has for the moment, moved them to the centre of the organisational management lexicon.

Although conceptual and measurement challenges obstruct the reporting of precise figures (Mokhtarian, Salomon, \& Choo, 2005), there is evidence that, increasingly, many workers are able (and prefer) to perform work-related tasks without having to be at a particular place of work. Allen, Golden and Shockley (2015) note that two data points are generally reported to support this claim. The first is the number or percentage of employees who choose to work away from the office, whilst the second is the number or percentage of organisations which allow workers to work away from the office. The American Community Survey, which measures the number of US employees who work from home at least half of the time, found an increase in the number of these employees from 1.8 million in 2005 to 3.9 million in 2015 (FlexJobs, 2017). Similarly, a 2015 Gallup 
poll found that $37 \%$ of Americans have telecommuted for work and $24 \%$ of them did so on more than half of their workdays (Jones, 2015). Data from Eurostat shows that around $5 \%$ of workers within the European Union typically worked from home, with an additional 10\% sometimes workedfrom home (Eurostat, 2018). The Covid-19 pandemic has led to an unprecedented increase in the number of individuals working remotely, and it is expected that in the wake of the pandemic, a new normal may emerge where a much larger proportion of workers will work remotely (e.g., Kantrowitz, 2020).

Despite its growing popularity, the practice of performing work away from a central location has not been meaningfully theorised, with a significant amount of conceptual confusion, overlap and ambiguity characterising much of the published literature (Raghuram, Hill, Gibbs, \& Maruping, 2018; Schweitzer \& Duxbury, 2010). Conceptual debates in the preceding two decades over the meaning of 'virtuality', and distinctions between more traditional work-forms vis-a-vis distributed work, telework and other flexible work arrangements, have yet to be resolved. The Covid-19 pandemic has sparked a high degree of interest in this domain and it is expected that in the wake of the pandemic, a new normal may emerge where a much larger proportion of workers will choose to work from their homes. Additionally, it is expected that many organisations have, as a result of the pandemic, rapidly adopted (and adapted to) the technological infrastructure and policies that enable employees to work from their homes. With these elements in place, remote work is likely to become a more permanent feature of many organisations. In the light of these developments, we argue that a conceptual framework that define the notions of distributedness and virtuality in relation to work practices at various levels of organisation represent an important gap in the current body of literature. The objective of the present article, accordingly, is to develop and present an integrative framework which addresses this gap.

To achieve this objective, we commence by reviewing definitions for a range of concepts which are frequently used in this domain. These include telework, telecommuting, remote work, distributed work and virtual work, as well as virtual teams, virtual organisations and distributed organisations. Based on these reviews, we identify the key characteristics of the phenomena they define, enabling us to differentiate between them and consider their relevance to different levels of analysis of organisational work. We discuss these characteristics about each concept and finally integrate them to form a conceptual framework with possible future research implications.

\section{Review of published definitions}

Distributed work has been defined in different ways, with such definitions often invoking a range of related concepts such as telework, telecommuting, remote work, distributed work and virtual work, as well as virtual teams, global virtual teams (GVT), distributed teams, virtual organisations and distributed organisations. Whilst these concepts vary in terms of focus and meaning, they all concern the central principle of the physical or geographical distribution of work - that is, work that is not performed at a single, centralised location. This section commences by presenting a collection of published definitions for each of these terms. Thereafter, we briefly discuss similarities and differences between the definitions. We consider, firstly, terms which describe the general practice of distributed work, before turning our attention to terms that describe the enactment of distributed work practices at different levels of organisation (e.g., telecommuting, virtual teams and virtual organisations).

The selection of these definitions was achieved with a non-random chain-selection process, beginning with a key seminal definition for each term. These seminal definitions were chosen as a result of being oft-cited sources for each term. After the inclusion of that definition, further definitions were discovered through the use of forward and backward literature searches, building the sampled collection over time to include both earlier definitions which had not received widespread use, and later definitions which provided more contexts. Additional definitions were selected if they were significantly different to the primary definition, as the focus of this article is to explore the breadth of definitions available and discover commonalities across definitions and terms. Definitions providing identical content for a single term were not included multiple times.

Because the present article is concerned with definitions, it is important to recognise that there are implicit principles which relate to their accuracy and usefulness. Firstly, we adopt the principle that a definition's preciseness should be considered relative to the domain in which it is utilised. Capurro and Hjorland (2005) accordingly, argue that:

$[S]$ tatements, and the concepts figuring in them, will be as precise and informative as the theory in whose language they are formed is precise and informative. For instance, I think it will be agreed that the Newtonian concept of mass has a more precise meaning than the concept of democracy. (p. 346)

It is our view that the domain of interest here, distributedwork patterns and practices, as a result of their dynamic, socio-material nature, resists precise definition. Secondly, we acknowledge that, in the construction of lexical definitions, a concept is defined through the use of other concepts and if the meanings of these latter concepts are themselves established by definition, 'it is clear that an infinite regress will result, unless the meanings of some concepts are known by other means' (Capurro \& Hjorland, 2005, p. 346). Our aim, accordingly, is not the development of absolute definitions, but rather the clarification and elucidation of distributed work practices through conceptual interrogation of existing definitions. 


\section{Terms describing general distributed work practices}

The first group of terms examined are those which describe different ways in which the practice of distributed work is organised. These terms include telework, distributed work, remote work and virtual work. Notably, these terms do not explicitly address the operations of work systems at particular levels of analysis (e.g., individual, unit or organisation), but describe the practice of distributed work in more general terms.

\section{Telework}

The first term to be examined is telework, as it has both been used as a term earlier than other terms and also, has been used to reference a wider scope of work. Table 1 provides a selection of published definitions for telework, ordered by date of publication.

Considerations of these definitions enable the identification of a number of the foundational principles of distributed work. The first and most important of these concern the existence of geographical distance between the location at which work is normally (or conventionally) performed and the location at which telework is performed. This is apparent in the phrase tele-work, with the Greek 'tele' meaning far or distant. Whilst telework is often associated with work being performed from home, care should be taken to not oversimplify the notion. Morganson et al.'s (2010) definition, for example, includes work that is performed from a satellite office, or the field. Hence, the term relies upon the notion of a conventional or regular place of work. Conceptually, however, this notion is problematic when a worker's conventional location of work is the field or one of many possible satellite offices.

The second principle, apparent in some though not all definitions, is that the ability of the worker to work at a distance often depends upon the utilisation of technology which mediates communication and coordination with co-workers. In principle, it is possible that certain types of work can be performed at a distance with minimal need for such communication or coordination, thus eliminating this as a definitional requirement. For example, a bookkeeper working through a box of paper-based accounts at home only to return to the office the next day, may not require during that day any form of communication or coordination with co-workers. It is apparent, accordingly, that the use of technology may be a common, even important, characteristic, but it is not a prerequisite.

A third principle worth noting is that telework is not considered in binary terms. Instead, it is a scale representing the proportion of overall working time spent working away from a conventional place of work. Taken to its extreme, this suggests that any person performing any amount of work away from their conventional workplace can be considered a teleworker. This extreme interpretation, however, strips the term of its utility for both research and practice purposes. It is more useful perhaps, to consider teleworkers as those who work away from conventional workplaces for some minimum proportion of their time.

\section{Remote work and distributed work}

Remote work and distributed work are often used interchangeably (O'Neill, Hambley, \& Chatellier, 2014) and, when considering the published definitions presented in Table 2, there seem to be little grounds for the conceptual distinction between the two terms.

Consideration of the definitions presented in Table 4 suggests that the terms remote work and distributed work align closely with that of telework, describing work arrangements that are in principle, similar. Perhaps the only distinction is that the definitions tend to avoid explicit reference to the notion of a conventional workplace, suggesting recognition that the advancement of the technologies which enable work coordination increasingly disconnects the performance of work activities from a particular physical location. Rockmann and Pratt (2015) provide a more specific conceptualisation by outlining four features that they argue, characterise distributed work. The first two, physical distance and the use of technology, overlap with earlier definitions. The third, reduced supervision requires consideration. It suggests that the physical co-location of a worker and his or her supervising

TABLE 1: A selection of telework definitions.

\section{Definition}

'Telecommuting is a subset of teleworking, a similarly coined term that includes all work-related substitutions of telecommunications and related information technologies for travel (from substitution of telephone calls or electronic mail for personal visits to the use of full-motion videoconferencing as a substitute for executive travel). In either case the emphasis is on substitution: the worker newly engaged in tele-X-ing is altering his/her previous travel behaviour.'

'Work arrangements in which employees perform their regular work at a site other than the ordinary workplace, supported by technological connections.'

'Work that relies on technology-mediated communication and sophisticated information-processing capabilities instead of colocation for the production and delivery of work outputs.'

'A broad term used to describe a variety of arrangements that involve working away from the employer's main campus ...' outside of the central office (including full-time work from home but not necessarily limited to home-based work) and includes work from home-based businesses, telecentres, and call centres, and even work within an organisation's central office between individuals who are interacting through the use of technology.'

Note: Please see the full reference list of the article, Henry, M.S., le Roux, D.B., \& Parry, D.A. (2020). Working in a post Covid-19 world: Towards a conceptual framework for distributed work. South African Journal of Business Management 51(1), a2155. https://doi.org/10.4102/sajbm.v51i1.2155, for more information.

\author{
Reference \\ Nilles, 1988, p. 301 \\ Fitzer, 1997, p. 65
}

Garrett and Danziger, 2007, p. 27

Morganson, Major, Oborn, Verive and Heelan, 2010, p. 579

Allen et al., 2015, pp. 42-43 
co-worker constitutes more or increased supervision. We argue that this may indeed be a consequence of remote work in certain settings, but that it is not a necessary consequence. Indeed, the argument can be made that the affordances of contemporary information systems which support remote work may, in some cases, increase rather than decrease the degree of supervision over workers (Bødker, 2016; Spivack \& Rubin, 2011). Nonetheless, it must be conceded that the nature of supervision changes when co-workers do not share a physical location. The fourth feature states that distributed work implies interpersonal connection between co-workers. Whilst the technological infrastructure utilised by many distributed workers (e.g., enterprise social media) support such an interpersonal connection, it's not clear to us that this is a defining feature. Two motivations for our position are offered. Firstly, many co-workers who are physically co-located utilise similar tools which support interpersonal connection to enhance communication and coordination (e.g., email). Secondly, it is foreseeable that distributed work can occur without interpersonal connection, mainly when such work is individual in nature and requires little or no coordination amongst co-workers.

\section{Virtual work}

A final term used to refer to a distributed work practice is that of virtual work. Table 3 provides a selection of published definitions for virtual work, ordered by date of publication.

The definitions provided in Table 3 suggest that virtual work describes very similar work arrangements than those described by distributed or remote work. The key difference, however, as implied by the term virtual, seems to be that virtual work is more closely associated with the notion of internet-based communication amongst distributed workers with the aim of creating the impression of real co-location. The term, however, describes this poorly as it is not the work itself that is virtual, but rather the co-location of cooperating workers. Terms like virtual team or virtual organisation are, in this sense more suitable. It may be argued however, that virtual work describes forms of distributed work which rely more heavily on frequent coordination and communication amongst co-workers and therefore, virtual co-location. Hence, whilst the work performed is very real, the co-location of the workers is virtual.

\section{Conclusion}

Based on the preceding sections, a number of conclusions may be drawn:

- First, it is evident that whilst subtle differences may exist for the definitions of particular authors, there is extensive overlap between the terms telework, distributed work, remote work and virtual work. In our view, the degree of overlap is such that conceptually distinguishing between these terms provided little theoretical value.

- Second, this overlap is centred around the notion of physical distance between two or more locations at which some form of related work activities are performed, with the location of the activity determined by the physical location of the worker performing it (as opposed to, for example, its location in the digital sphere). In its simplest form the arrangement involves work performed at a location other than a particular worker's conventional workplace. However, the terms are also used to describe related work activities performed by workers working at different workplaces, whilst appearing conventional to each of them.

- Underlying the various concepts is the general principle that the work activities performed across these distances

TABLE 2: A selection of remote and distributed work definitions.

\begin{tabular}{|c|c|c|}
\hline Term & Definition & Reference \\
\hline Remote work & $\begin{array}{l}\text { 'A work arrangement in which the employee resides and works at a location beyond the local commuting area of the } \\
\text { employing organisation's worksite; generally includes full-time telework and may result in a change in duty location to the } \\
\text { alternative worksite.' }\end{array}$ & $\begin{array}{l}\text { US Office of Personnel } \\
\text { Management, 2013, p. } 18\end{array}$ \\
\hline $\begin{array}{l}\text { Remote work and } \\
\text { distributed work }\end{array}$ & $\begin{array}{l}\text { 'The terms remote work and distributed work are generally considered broader than telecommuting and can denote any } \\
\text { form of work not conducted in the central office, including work at branch locations and differing business units.' }\end{array}$ & Allen et al., 2015, pp. 43-44 \\
\hline Distributed work & $\begin{array}{l}\text { 'Employees work over geographical boundaries and to some extent work with computer-mediated communication (CMC) } \\
\text { in order to achieve a common goal.' }\end{array}$ & $\begin{array}{l}\text { Bosch-Sijtsema and Sivunen, 2013, } \\
\text { p. } 160\end{array}$ \\
\hline Distributed work & $\begin{array}{l}\text { 'Distributed work [...] is marked by four key features that differentiate it from more traditional office work. First, distributed } \\
\text { work is different from more traditional office work because of the physical distance involved [...] Second, this physical } \\
\text { distance is managed by a reliance on communication technology [...] A third feature defining distributed work is reduced } \\
\text { supervision }[. . .] \text { Fourth, [...] distributed work requires that individuals are interpersonally connected with some other } \\
\text { individuals: this could be a single person, a team, or others in an organization. In other words, to be distributed means } \\
\text { one has to be distributed from others.' }\end{array}$ & $\begin{array}{l}\text { Rockmann and Pratt, 2015, pp. } \\
\text { 151-152 }\end{array}$ \\
\hline
\end{tabular}

Note: Please see the full reference list of the article, Henry, M.S., le Roux, D.B., \& Parry, D.A. (2020). Working in a post Covid-19 world: Towards a conceptual framework for distributed work. South African Journal of Business Management 51(1), a2155. https://doi.org/10.4102/sajbm.v51i1.2155, for more information.

TABLE 3: A selection of virtual work definitions.

\begin{tabular}{|c|c|}
\hline Definition & Reference \\
\hline $\begin{array}{l}\text { 'An all-encompassing term representing work environments where employees are physically separated and/or temporally } \\
\text { separated from their co-workers or their work location some or all of the time, and perform interdependent work activities.' }\end{array}$ & Watson-Manheim and Belanger, 2002, p. 1 \\
\hline $\begin{array}{l}\text { 'Working from home, satellite offices or on the road [...] or as ad hoc groups of professionals who team across the internet } \\
\text { around a common topic.' }\end{array}$ & $\begin{array}{l}\text { Chudoba, Wynn, Lu and Watson-Manheim, 2005, } \\
\text { p. } 15\end{array}$ \\
\hline $\begin{array}{l}\text { 'A broader term often used to describe individuals, groups of individuals, or organizations who do not interact face-to-face } \\
\text { because of geographic dispersion yet who interact using technology in some fashion.' }\end{array}$ & Allen et al., 2015, p. 43 \\
\hline
\end{tabular}


are systemically interdependent to varying degrees. Where such interdependence is high, the need for more frequent and detailed communication and coordination increases. This, in turn, enhances the relevant workers' reliance upon technological infrastructure that creates the impression of co-location. It follows that the nature of the work performed would, to some extent, determine the possibilities in terms of worker distribution. Specifically, where the properties of a particular activity require the worker to be in a particular physical location, the possibility of remote work disappears. Unless or until the technology is adopted such that it makes the requirement of the worker's physical presence redundant.

- An important observation is that there is no consensus on (or reference to) the amount of distance between work activities that is required to describe them as remote, distributed or virtual. However, the amount of distance would determine the possibility of occasions for physical co-location at regular intervals (e.g., meetings, workshops). We may imagine, for example, that co-workers distributed across the same city would be able to meet face to face more readily than those distributed across multiple countries.

- In much the same way, there seems to be a continuum describing the proportion of a worker's time spent working remotely. We argue accordingly, that the practice of distributed work should be described in relation to two continua. First, workers can be more or less physically distributed and second, they may remain in such a situation for more or less of their working time.

\section{Terms describing distributed work at different levels of organisation}

Having examined the set of terms that describe distributed work practices broadly, we now turn our attention to terms that relate to the manner in which these practices are enacted at different levels of organisation. We consider firstly, the individual level at which focus falls on the manner in which a worker performs work away from a conventional place of work. Thereafter we consider the team level where focus falls on the physical distribution of workers that cooperate in shared projects. Lastly, we consider virtual or distributed organisations.

\section{Telecommuting}

One of the first widely used terms for distributed work is telecommuting, and it generally refers to the individual level of work. Allen et al. (2015), based on their review of definitions for telecommuting, find that most of the definitions adopt the two premises identified in the preceding section concerning distributed work practice physical distance between worker and conventional place of work, and the use of technology to facilitate communication and coordination with co-workers. They note, however, that:

$[B]$ eyond these two generally accepted premises, many definitions lacked an acknowledgment of the variance in the extent of telecommuting practiced (from a few hours per week to nearly full-time), the type of employment relationship (e.g., part of a larger organisation, home based business, or outsourced independent contractor), and the location of primary work done outside the central office (e.g., home, locations outside of major cities but near residences, call centers, sales locations, hotels, airports). (p. 44)

Table 4 provides a selection of published definitions for telecommuting, ordered by date of publication.

As is evident in Table 4, the definitions generally focus on the individual and operate upon the assumption that he or she has a conventional place of work. Telecommuting represents a change in location away from that place with various information and communication technologies (ICTs) utilised to facilitate communication in the absence of face-to-face interaction. Reference is also made to the degree or intensity at which telecommuting is practised, from rarely, to part-time or even full-time telecommuting. In this regard, the definitions reveal that, when using the

TABLE 4: A selection of telecommuting definitions.

\begin{tabular}{|c|c|}
\hline Definition & Reference \\
\hline 'The partial or total substitution of telecommunications, with or without the assistance of computers, for the twice-daily commute to work.' & Nilles, 1988, p. 301 \\
\hline 'The use of telecommunications technology to partially or completely replace the commute to and from work.' & Mokhtarian, 1991, p. 1 \\
\hline $\begin{array}{l}\text { 'Three principal components of telecommuting can be identified: utilization of information technology (IT), link with an organization, and } \\
\text { de-localization of work.' }\end{array}$ & $\begin{array}{l}\text { Pinsonneault and Boisvert, } \\
\text { 2001, p. } 4\end{array}$ \\
\hline 'Working some portion of time away from the conventional workplace, often from home, and communicating by way of computer-based technology.' & Golden, 2006, p. 319 \\
\hline $\begin{array}{l}\text { 'Perform part of their roles outside the company's physical boundary using information technology as the main tool for operation and } \\
\text { communication [...] Although this work mode may also encompass, for example, working in multiple satellite offices or other remote locations } \\
\text { away from home, telecommuters most commonly allocate their work time between an office and home.' }\end{array}$ & $\begin{array}{l}\text { Golden, Veiga and Simsek, } \\
2006, \text { p. } 1340\end{array}$ \\
\hline 'Work conducted from home that is often supported by telecommunications technology.' & $\begin{array}{l}\text { Kossek, Lautsch and Eaton, } \\
2006, \text { p. } 347\end{array}$ \\
\hline $\begin{array}{l}\text { 'Telecommuting is an alternative work arrangement in which employees perform tasks elsewhere that are normally done in a primary or central } \\
\text { workplace, for at least some portion of their work schedule, using electronic media to interact with others inside and outside the organization.' }\end{array}$ & $\begin{array}{l}\text { Gajendran and Harrison, } \\
2007, \text { p. } 1525\end{array}$ \\
\hline 'The use of ICT to replace or substitute for work environments that required individuals to commute to a traditional office.' & $\begin{array}{l}\text { Bélanger, Watson-Manheim } \\
\text { and Swan, 2013, p. } 1257\end{array}$ \\
\hline $\begin{array}{l}\text { 'Telecommuting is a work practice that involves members of an organization substituting a portion of their typical work hours (ranging from a } \\
\text { few hours per week to nearly full-time) to work away from a central workplace-typically principally from home-using technology to interact } \\
\text { with others as needed to conduct work tasks.' }\end{array}$ & Allen et al., 2015, p. 44 \\
\hline
\end{tabular}
with others as needed to conduct work tasks.

Note: Please see the full reference list of the article, Henry, M.S., le Roux, D.B., \& Parry, D.A. (2020). Working in a post Covid-19 world: Towards a conceptual framework for distributed work. South African Journal of Business Management 51(1), a2155. https://doi.org/10.4102/sajbm.v51i1.2155, for more information.

$\mathrm{ICT}$, Information and communication technologies. 
term, researchers often adopt the assumption that telecommuting is practised for a portion of the worker's overall work time. Consequently, the term does not apply readily to full-time distributed workers for whom the conventional place of work is away from co-workers. Golden and Veiga (2005) share this view, arguing that the frequency of telecommuting is not always considered in studies, and the distinction between 'one day per month' and ' $90 \%$ of work days' has a large impact on the variables investigated.

\section{Virtual teams}

Within the lexicon of distributed work, the term primarily used to describe a group of cooperating workers is virtual team. Table 5 provides a selection of published definitions for the term, ordered based on the date of publication.

As shown in Table 5, the definitions cover a broad range of possible work arrangements of teams. Whilst the term virtual team is the most frequently used, virtual group and GVT are also used. Some definitions emphasise the short-term, or non-hierarchical nature of virtual teams (Jarvenpaa \& Leidner, 1999; Miles \& Snow, 1986), whilst others focus on the physical distance between team members and the use of ICTs to create the impression of co-location (Berry, 2011; Hertel et al., 2005). Global virtual teams, as the term suggests, are typically constituted by workers in or from different nationalities, recognising the possibility of cultural and functional background differences between team members (Harvey, Novicevic, \& Garrison, 2005), which may introduce unique managerial or operational challenges. However, as more virtual teams gain global reach, the distinction between virtual teams and GVTs is becoming less prominent (Daim et al., 2012). As Jimenez, Boehe, Taras and Caprar (2017) note:

$[O]$ rganisations often don't even emphasize the 'global' and 'virtual' aspects when referring to their GVTs [global virtual teams], as working across boundaries has become the norm, rather than an exception, with members of such teams being not just full-time or part-time employees, but also freelancers, contractors, suppliers, and other collaborators. (p. 341)

\section{Virtual or distributed organisation}

The third level of organisation we consider is that of the organisation as a whole. Table 6 provides a selection of published definitions for the term virtual organisation, ordered and based on the date of publication.

As seen in Table 6, the term virtual organisation is problematic, with the definition most commonly referring to either a temporary organisation consisting of employees from multiple different organisations (Jarvenpaa \& Shaw, 1998; Priego-Roche et al., 2016), or a single organisation consisting of one or more virtual teams (DeSanctis \& Monge, 1998). The

TABLE 5: A selection of virtual team definitions.

\begin{tabular}{|c|c|c|}
\hline Term & Definition & Reference \\
\hline Virtual team & $\begin{array}{l}\text { 'Members (1) physically remain on different continents and in different countries, }(2) \text { interact primarily through the use of } \\
\text { computer-mediated communication technologies (electronic mail, videoconferencing, etc.), and (3) rarely or never see } \\
\text { each other in person.' }\end{array}$ & $\begin{array}{l}\text { Jarvenpaa, Knoll and Leidner, } \\
1998, \text { p. } 30\end{array}$ \\
\hline Global virtual team & 'A temporary, culturally diverse, geographically dispersed, electronically communicating work group.' & $\begin{array}{l}\text { Jarvenpaa and Leidner, 1999, } \\
\text { p. } 792\end{array}$ \\
\hline Virtual group & 'Virtual groups exist when several teleworkers are combined and each member reports to the same manager.' & $\begin{array}{l}\text { Hertel, Geister and Konradt, } \\
\text { 2005, p. } 71\end{array}$ \\
\hline Virtual team & $\begin{array}{l}\text { 'Virtual teams consist of (a) two or more persons who (b) collaborate interactively to achieve common goals, while (c) at least } \\
\text { one of the team members works at a different location, organization, or at a different time so that (d) communication and } \\
\text { coordination is predominantly based on electronic communication media (e-mail, fax, phone, video conference, etc.).' }\end{array}$ & Hertel et al., 2005, p. 71 \\
\hline Virtual team & $\begin{array}{l}\text { 'Virtual teams are groups of geographically and/or organizationally distributed participants who collaborate towards a shared } \\
\text { goal using a combination of information and communication technologies (ICT) to accomplish a task.' }\end{array}$ & $\begin{array}{l}\text { Bjørn and Ngwenyama, 2009, } \\
\text { p. } 228\end{array}$ \\
\hline Virtual team & $\begin{array}{l}\text { 'A virtual team has the following six attributes, sharing the first four with almost all teams: } \\
\text { - The team usually but not always has a definable and limited membership, and there is awareness by team members of } \\
\text { this shared membership, and even if membership changes somewhat, the team remains intact. } \\
\text { - The members of the team function interdependently, usually with a shared sense of purpose that is either given to them or } \\
\text { constructed by the team itself. } \\
\text { - The members of the team are jointly responsible for outcomes. } \\
\text { - The members of the team collectively manage their relationships across (and perhaps between) organizational boundaries. } \\
\text { - The members of the team may be geographically dispersed. } \\
\text { communication to accomplish their tasks.' }\end{array}$ & Berry, 2011, pp. 17-18 \\
\hline
\end{tabular}

Note: Please see the full reference list of the article, Henry, M.S., le Roux, D.B., \& Parry, D.A. (2020). Working in a post Covid-19 world: Towards a conceptual framework for distributed work. South African Journal of Business Management 51(1), a2155. https://doi.org/10.4102/sajbm.v51i1.2155, for more information.

TABLE 6: A selection of virtual organisation definitions.

\section{Definition}

'A collection of geographically distributed, functionally and/or culturally diverse entities that are linked by electronic forms of communication and rely on lateral, dynamic relationships for coordination.'

'A virtual organization must rely on a set of temporary project collaborations between individuals from several organizations.' 'A temporary or permanent collection of geographically dispersed individuals, groups, organizational units - which do or do not belong to the same organization - or entire organizations that depend on electronic linking in order to complete the production process.'

'An alliance of organizations linked by a partnership for dealing with emerging challenges.'

'Geographically distributed organizations whose members are bound by a long-term common interest or goal, and who largely communicate and coordinate their work through information technology.'

Note: Please see the full reference list of the article, Henry, M.S., le Roux, D.B., \& Parry, D.A. (2020). Working in a post Covid-19 world: Towards a conceptual framework for distributed work. South African Journal of Business Management 51(1), a2155. https://doi.org/10.4102/sajbm.v51i1.2155 for more information.

Reference
DeSanctis and Monge, 1998, p. 1

Jarvenpaa and Shaw, 1998, p. 35 Travica, 1997, p. 3

Priego-Roche, Front and Rieu, 2016, p. 439 Grabowski and Roberts, 2019, p. 512 
term virtual, accordingly, seems to be used interchangeably to refer to either the temporary nature of the organisation, its composition of members from different (other) organisations, the physical distributedness of the organisation's workers, or some combination of these properties.

Importantly, virtual organisations and distributed organisations should not be considered synonymous. Table 7 provides two published definitions for the term distributed organisation.

The term is used to describe large organisations with multiple offices or sites, without explicitly acknowledging the possibility or requirement of telecommuters or virtual teams (Oliver \& Kandadi, 2006). However, as seen in the definition proposed by Ellison et al. (2015), the term is sometimes used to refer to a combination of the physical distribution of sites and work arrangements that support the distributedness of workers at individual and team level. However, there is no clear distinction between, for example, workers at multiple offices and workers that telecommute (Munkvold, 1999).

The intensive use of computer-based technologies in the current corporate environment implies that all organisations exhibit some degree of virtuality (Marlow, Lacerenza, \& Salas, 2017). Accordingly, we argue that, for the present analysis, the notion of a virtual organisation provides little additional conceptual value beyond that of virtual teams. A virtual organisation can be conceptualised as a (potentially large) virtual team or collection of such teams characterised by physical distance between at least some teams and team members. Like virtual teams, they rely upon ICTs to facilitate communication and coordination of work systems; have shared objectives, and may be constituted of workers simultaneously employed by other organisations. As a result of these similarities, we see little conceptual value emerging from distinctions between them.

We argue however that distributed organisations that coordinate work systems across multiple, geographically separated sites (e.g. office buildings, factories, warehouses) represent a different phenomenon. Such organisations would, in principle face the same challenges as virtual organisations that result from a limitation in the proportion of communication amongst workers at different sites that can occur face to face. However, it is obvious that the management of large organisations with multiple sites (potentially across

TABLE 7: A selection of definitions for distributed organisation.

\begin{tabular}{ll}
\hline Definition & Reference \\
\hline $\begin{array}{l}\text { 'Organizations consisting of two or more semi-autonomous } \\
\text { units in different geographical locations.' }\end{array}$ & Munkvold, 1999, p. 260 \\
$\begin{array}{ll}\text { Organisations today are more distributed, turning to } \\
\text { more-networked organisational forms, virtual teams, } \\
\text { and distance work arrangements. }\end{array}$ & $\begin{array}{l}\text { Ellison, Gibbs and } \\
\text { Weber, 2015 }\end{array}$ \\
\hline
\end{tabular}

Note: Please see the full reference list of the article Henry, M.S., le Roux, D.B., \& Parry, D.A. (2020). Working in a post Covid-19 world: Towards a conceptual framework for distributed work. South African Journal of Business Management 51(1), a2155. https://doi.org/10.4102/ sajbm.v51i1.2155, for more information. multiple countries) present a set of unique challenges which are perhaps effectively captured by the phrase distributed organisation.

\section{Conclusions}

Based on the preceding sections, a number of conclusions may be drawn:

- Firstly, in accordance with Jimenez et al. (2017), we argue that when the notion of virtuality is distilled to its essential principles, it is evident that any contemporary knowledge worker is to some degree, a teleworker, and every team or organisation is to some degree, virtual. By extension we accept that there may be a very wide variety of different work patterns and organisational forms that may be described as virtual.

- Secondly, the key conceptual challenge, it seems is determining how much virtuality and distributedness is required to justify the use of the phrases. For example, a large organisation, in which all but a very small number of workers perform work from a shared office, is clearly different to a small organisation without any central location of work. Whilst both may, in principle, exhibit degrees of virtuality and distributedness, it is obvious that they are on different ends of the spectrum. Failure to acknowledge and describe this spectrum strips the relative phrases of their conceptual value.

- Thirdly, conceptual value can be maintained by considering the notions of virtuality and distributedness at the individual, team and organisational levels in terms of intensity or proportionality; that descriptions at each level should be possible independent of work arrangements at the other levels. For example, a team can be described as virtual (at the team level) despite not containing any telecommuting members (at the individual level). Likewise, an organisation should not be described as distributed simply for having a small proportion of individuals who sometimes telecommute.

- Lastly, we propose that the term distributed organisation be used to specifically denote large organisations with multiple sites that are geographically distributed across multiple towns, cities and countries.

\section{An integrated framework of distributed and virtual work}

Based on the reviewed conceptualisations of the various forms and levels of distributed and virtual work practices, the present section proposes a conceptual framework in which we integrate the prominent principles identified. We commence by outlining the main premises of our framework, after which we discuss its application as an analytic lens to various possible organisational scenarios. Finally, we identify and briefly discuss the various factors which, based on our framework, may influence decision making in terms of the adoption of policies that allow or promote distributed and virtual work practices. 


\section{Virtuality and distributedness}

We base our framework firstly, on the distinction between virtuality and distributedness, and secondly, on the premise that the two concepts can be combined to describe particular genres of work practices. In line with a majority of extant conceptualisations, we define distributedness to describe: $a$ combination of two factors: the degree of physical (geographical) separation between locations where work is performed; and the proportion of time that work is performed whilst work locations are physically separated.

We define virtuality as: the degree to which work activities are interdependent, and the extent to which communication and coordination of these activities is mediated by ICTs.

By combining these two factors, as shown in Table 8, it becomes possible to describe a work practice in terms of both its distributedness and virtuality. For example, when interdependent work activities are primarily conducted across small distances (e.g. different floors of the same office building), and communication amongst co-workers primarily occurs in the form of face-to-face meetings, the practice can be described as being both low in virtuality and distributedness. If however, almost all communication amongst the relevant workers is mediated by ICTs, we may describe the practice as high in virtuality but low in distributedness. It is expected, consequently, that high levels of distributedness would obstruct regular face-to-face interaction and should therefore imply greater virtuality. Nonetheless, when the work activities conducted across these distances are not highly interdependent, there may be little need for coordinated cooperation and by extension, virtual interaction.

\section{Virtuality and distributedness at levels of organisation}

The framework extends the combination of distributedness and virtuality by considering the intersection of these continua at three levels of organisation: individual, team and organisation. Table 9 represents level-specific descriptors of distributedness and virtuality at each level. At the individual level distributedness assumes either a conventional workplace or co-workers from which the individual is separated when working, and describes the degree of physical distance that characterises this separation as well as the proportion of time the worker spends working across distance. At the team level distributedness describes the general amount of physical separation between team members, as well as the proportion of time the team spends working across this distance. At the organisational level distributedness assumes an organisation with multiple work sites (e.g. office buildings, factories, warehouses) and describes the amount of physical separation between these sites of work. Across all three levels, virtuality describes the proportion of work-related communication and coordination that occurs using ICTs to overcome the inability, as a result of distributedness, to interact face-to-face. Importantly, our definition of virtuality does not refer to either the temporary nature of a team or organisation, nor the possibility that a team or organisation may be constituted by workers that are simultaneously employed elsewhere. We argue that attempting to define virtuality so broadly as to accommodate these properties, in addition to communication and coordination patterns, would detract from the term's utility and value.

Having defined distributedness and virtuality at each of the organisational levels, we briefly outline key factors which, based on our analysis, would impact the operational possibilities at the levels of individuals and teams. Based on our narrow definition of distributed organisations as the separation between multiple worksites, these factors do not apply readily at that level. Nonetheless, insofar as distributed organisations have individuals and teams that work in a distributed manner, the factors apply. Table 10 outlines four factors emerging from our analysis:

- Interdependence between tasks describes the degree to which work activities rely upon input from, or produce input to activities performed by co-workers.

TABLE 8: Combining distributedness and virtuality to describe work practices.

\begin{tabular}{lll}
\hline Virtuality & Lower distributedness & Higher distributedness \\
\hline Higher & Lower degree of physical separation between workers; intensive use of ICTs & $\begin{array}{l}\text { Higher degree of physical separation between workers; low degree of face-to-face } \\
\text { interaction; intensive use of ICTs }\end{array}$ \\
Lower & $\begin{array}{l}\text { Lower degree of physical separation between workers; higher degree of } \\
\text { face-to-face interaction }\end{array}$ & $\begin{array}{l}\text { Higher degree of physical separation between workers; lower need for } \\
\text { communication as a result of low activity interdependence }\end{array}$ \\
\hline
\end{tabular}

ICT, Information and communication technologies.

TABLE 9: Organisational levels connected with distributedness and virtuality.

\begin{tabular}{|c|c|c|c|}
\hline \multirow[t]{2}{*}{ Level } & \multicolumn{2}{|l|}{ Distributedness } & \multirow[t]{2}{*}{ Virtuality } \\
\hline & Physical distance & Proportion of time & \\
\hline Individual & $\begin{array}{l}\text { The amount of physical separation between the } \\
\text { individual and other members of the organisation or } \\
\text { conventional work site. }\end{array}$ & $\begin{array}{l}\text { The proportion of time an individual worker spends working away } \\
\text { from other members of the organisation or conventional work site }\end{array}$ & $\begin{array}{l}\text { The proportion of communication } \\
\text { and coordination of work that } \\
\text { occur using ICT. }\end{array}$ \\
\hline Team & $\begin{array}{l}\text { The amount of physical separation between members of } \\
\text { a team. }\end{array}$ & $\begin{array}{l}\text { The proportion of time team members spend working separated } \\
\text { from each other. }\end{array}$ & \\
\hline Organisation & $\begin{array}{l}\text { The number of organisational work sites and the amount of } \\
\text { physical separation between them. }\end{array}$ & - & - \\
\hline
\end{tabular}

ICT, Information and communication technologies. 
TABLE 10: Factors that influence organisational policy options for distributedness and virtuality at different organisational levels.

\begin{tabular}{|c|c|c|c|c|}
\hline Level & Interdependence of tasks & Nature of work & Technological environment & Temporal distance \\
\hline Individual & $\begin{array}{l}\text { The degree of interdependence between } \\
\text { tasks performed by the individual and } \\
\text { other members of the organisation }\end{array}$ & $\begin{array}{l}\text { The degree to which the work } \\
\text { performed requires the worker to } \\
\text { be in a particular physical location. }\end{array}$ & $\begin{array}{l}\text { The degree to which the ICT infrastructure } \\
\text { supports communication and coordination } \\
\text { of work between the individual and other } \\
\text { members of the organisation. }\end{array}$ & $\begin{array}{l}\text { The degree to which the individual's work } \\
\text { requires synchronous communication } \\
\text { with other members of the organisation. }\end{array}$ \\
\hline Team & $\begin{array}{l}\text { The degree of interdependence between } \\
\text { tasks performed by team members }\end{array}$ & $\begin{array}{l}\text { The degree to which the work } \\
\text { performed requires the team to be } \\
\text { co-located. }\end{array}$ & $\begin{array}{l}\text { The degree to which the ICT infrastructure } \\
\text { supports communication and coordination } \\
\text { of work between team members. }\end{array}$ & $\begin{array}{l}\text { The degree to which the team's work } \\
\text { requires synchronous communication } \\
\text { amongst members. }\end{array}$ \\
\hline
\end{tabular}

ICT, Information and communication technologies.

Greater interdependence implies a higher need for communication and coordination.

- Nature of work refers to the degree to which the type of work performed requires the worker or team to be co-located. For example, a dentist's co-location with both his patient and equipment is a precondition for his or her ability to perform work activities.

- Technological environment describes the ICT infrastructure that is available to support the communication and coordination of work between individuals and teams that are not co-located.

- Finally, temporal distance refers to the degree to which an individual or team's coordination depends upon synchronous communication and coordination. For example, it may not be feasible for a virtual team that is distributed across different time zones to effectively perform work that requires synchronous communication.

\section{Discussion}

In this article, we investigated the lexicon of distributed work practices by reviewing published definitions for a wide variety of terms frequently used in this domain. Our findings support the argument that a significant amount of conceptual confusion, overlap and ambiguity characterise much of the published literature (Raghuram et al., 2018; Schweitzer \& Duxbury, 2010). In the context of the dramatic changes in work practises as a result of the Covid-19 pandemic, we developed a novel conceptual framework by systematically untangling the complicated web of terminology that describes distributed work at various levels of analysis. The framework builds primarily upon conceptual distinction between distributedness and virtuality, and the combination of these distinct concepts to describe organisational work scenarios.

The rapid advancement and uptake of ICTs that support communication and collaboration amongst workers that are not co-located imply that elements of distributedness and virtuality have become a common feature of contemporary organisations. These developments blur the boundaries between conventional work practices characterised by face-to-face interaction amongst co-workers, and emerging forms of work characterised by very high degrees of distributedness and intensive application of ICTs in all aspects of the operation. We propose that the Covid-19 pandemic will advance the blurring of these boundaries even further as an increasing number of 'conventional' organisations adopt policies that promote distributed work practices. Against this backdrop, our framework promotes a succinct but nuanced set of conceptualisations which build upon the essential principles of distributed work which were identified through analysis of a large collection of published definitions.

We foresee that the framework will provide researchers with a conceptual foundation when conducting empirical investigations of work practices that involve degrees of distributedness and virtuality. Specifically, the framework supports descriptions of specific work settings by directing researchers' attention to the factors that distinguish them. For example, whilst many a divers teams may be described as virtual, the framework provides a basis for indicating how their distributedness and virtuality make them different from each other and, by extension, support investigation of the role of these differences in their operation. Practitioners, on the other hand, may find value in our framework by using the factors outlined in Table 10 as a starting point for decision making about distributed work policies. Whilst far from complete, the factors will serve to support deliberation by directing managers' attention to an initial range of considerations. This can enhance the effectiveness of policy formulation, as well as its communication to workers.

Whilst we see our fairly narrow conceptualisations of distributedness and virtuality as the strength of our framework, we are aware that they are not without limitations. Most notably perhaps is the fact that the framework is mostly ignorant of two factors. Firstly, it does not address differences in the types of contracts workers have with organisations (e.g., freelance, part-time, full-time). Secondly, it does not explicitly address cross-organisation collaboration, or organisational forms set up for temporary purposes. We argue that these factors fall outside the scope of our framework which is aimed specifically at describing work-related communication and coordination across distance.

\section{Conclusion}

We foresee that the aftermath of the Covid-19 pandemic will be characterised by the rapid adoption of a wide variety of distributed work practices, creating various managerial challenges and important new research questions. We hope that the conceptual clarity in the framework proposed in this article serves to assist both practitioners and researchers in their navigation of this potentially turbulent period. However, we realise that it may in many ways, lack the rigour and flexibility required to make it useful across all contexts 
and we encourage other scholars to critically evaluate our work and improve upon it.

\section{Acknowledgements Competing interests}

The authors have declared that no competing interests exist.

\section{Authors' contributions}

All authors contributed equally to this work.

\section{Ethical consideration}

This article followed all ethical standards for research.

\section{Funding information}

This research received no specific grant from any funding agency in the public, commercial or not-for-profit sectors.

\section{Data availability statement}

The authors confirm that the data supporting the findings of this study are available within the article.

\section{Disclaimer}

The views and opinions expressed in this article are those of the authors and do not necessarily reflect the official policy or position of any affiliated agency of the authors.

\section{References}

Allen, T.D., Golden, T.D., \& Shockley, K.M. (2015). How effective is telecommuting? Assessing the status of our scientific findings. Psychological Science in the Public
Interest, 16(2), 40-68. https://doi.org/10.1177/1529100615593273

Bélanger, F., Watson-Manheim, M.B., \& Swan, B.R. (2013). A multi-level sociotechnical systems telecommuting framework. Behaviour \& Information Technology, 32(12), 1257-1279. https://doi.org/10.1080/0144929X.2012.705894

Berry, G.R. (2011). Enhancing effectiveness on virtual teams: Understanding why traditional team skills are insufficient. The Journal of Business Communication (1973), 48(2), 186-206. https://doi.org/10.1177/0021943610397270

Bjørn, P., \& Ngwenyama, O. (2009). Virtual team collaboration: Building shared meaning, resolving breakdowns and creating translucence. Information Systems Journal, 19(3), 227-253. https://doi.org/10.1111/j.1365-2575.2007.00281.x

$\mathrm{B} \emptyset \mathrm{dker}, \mathrm{S}$. (2016). Rethinking technology on the boundaries of life and work. Personal Ubiquitous Computing, 20(4), 533-544. https://doi.org/10.1007/s00779-0160933-9

Bosch-Sijtsema, P.M., \& Sivunen, A. (2013). Professional virtual worlds supporting computer-mediated communication, collaboration, and learning in geographically distributed contexts. IEEE Transactions on Professional Communication, 56(2), distributed contexts. IEEE Transactions on Professional
160-175. https://doi.org/10.1109/TPC.2012.2237256

Capurro, R., \& Hjorland, B. (2005). The concept of information. Annual Review of Information Science and Technology, 37(1), 343-411. https://doi.org/10.1002/ aris. 1440370109

Chudoba, K.M., Wynn, E., Lu, M., \& Watson-Manheim, M.B. (2005). How virtual are we? Measuring virtuality and understanding its impact in a global organization. Information Systems Journal, 15(4), 279-306. https://doi.org/ 10.1111/j.1365-2575.2005.00200.x

Daim, T.U., Ha, A., Reutiman, S., Hughes, B., Pathak, U., Bynum, W., \& Bhatla, A. (2012). Exploring the communication breakdown in global virtual teams. International Journal of Project Management, 30(2), 199-212. https://doi.org/10.1016/j. ijproman.2011.06.004

DeSanctis, G., \& Monge, P. (1998). Communication processes for virtual organizations. Journal of Computer-Mediated Communication, 3(4), JCMC347. https://doi. org/10.1111/j.1083-6101.1998.tb00083.x

Ellison, N.B., Gibbs, J.L., \& Weber, M.S. (2015). The use of enterprise social network sites for knowledge sharing in distributed organizations: The role of organizational affordances. American Behavioral Scientist, 59(1), 103-123. https://doi. org/10.1177/0002764214540510
Eurostat. (2018). Working from home in the EU. Retrieved from https://ec.europa.eu/ eurostat/web/products-eurostat-news/-/DDN-20180620-1. Fitzer, M.M. (1997). Managing from Afar: Performance and rewards in a
telecommuting environment. Compensation \& Benefits Review, 29(1), 65-73. https://doi.org/10.1177/088636879702900110

FlexJobs. (2017). Remote work grows $159 \%$ since 2005: FlexJobs \& GWA report. FlexJobs Job Search Tips and Blog. Retrieved from https://www.flexjobs.com/ $\mathrm{blog} /$ post/flexjobs-gwa-report-remote-growth/.

Gajendran, R.S., \& Harrison, D.A. (2007). The good, the bad, and the unknown about telecommuting: Meta-analysis of psychological mediators and individual consequences. Journal of Applied Psychology, 92(6), 1524-1541. https://doi. org/10.1037/0021-9010.92.6.1524

Garrett, R.K., \& Danziger, J.N. (2007). Which telework? Defining and testing a taxonomy of technology-mediated work at a distance. Social Science Computer Review, 25(1), 27-47. https://doi.org/10.1177/0894439306293819

Golden, T.D. (2006). The role of relationships in understanding telecommuter satisfaction. Journal of Organizational Behavior, 27(3), 319-340. https://doi. org/10.1002/job.369

Golden, T.D., \& Veiga, J.F. (2005). The impact of extent of telecommuting on job satisfaction: Resolving inconsistent findings. Journal of Management, 31(2), 301-318. https://doi.org/10.1177/0149206304271768

Golden, T.D., Veiga, J.F., \& Simsek, Z. (2006). Telecommuting's differential impact on work-family conflict: Is there no place like home? Journal of Applied Psychology, 91(6), 1340-1350. https://doi.org/10.1037/0021-9010.91.6.1340

Grabowski, M., \& Roberts, K.H. (2019). Reliability seeking virtual organizations: Challenges for high reliability organizations and resilience engineering. Safety Science, 117, 512-522. https://doi.org/10.1016/j.ssci.2016.02.016

Harvey, M., Novicevic, M.M., \& Garrison, G. (2005). Global virtual teams: A human resource capital architecture. The International Journal of Human Resource Management, 16(9), 1583-1599. https://doi.org/10.1080/09585190500239119

Hertel, G., Geister, S., \& Konradt, U. (2005). Managing virtual teams: A review of current empirical research. Human Resource Management Review, 15(1), 69-95. https://doi.org/10.1016/j.hrmr.2005.01.002

Jarvenpaa, S.L., Knoll, K., \& Leidner, D.E. (1998). Is anybody out there? Antecedents of trust in global virtual teams. Journal of Management Information Systems, 14(4), 29-64. https://doi.org/10.1080/07421222.1998.11518185

Jarvenpaa, S.L., \& Leidner, D.E. (1999). Communication and trust in global virtual teams. Organization Science, 10(6), 791-815. https://doi.org/10.1287/ orsc.10.6.791

Jarvenpaa, S.L., \& Shaw, T.R. (1998). Global virtual teams: Integrating models of trust In P. Sieber, \& J. Griese (Eds.), Organizational Virtualness, 35-52.

Jimenez, A., Boehe, D.M., Taras, V., \& Caprar, D.V. (2017). Working across boundaries: Current and future perspectives on global virtual teams. Journal of Internationa Management, 23(4), 341-349. https://doi.org/10.1016/j.intman.2017.05.001

Jones, J.M. (2015). In U.S., telecommuting for work climbs to $37 \%$. Gallup. Retrieved from https://news.gallup.com/poll/184649/telecommuting-work-climbs.aspx.

Kantrowitz, A. (2020). Twitter will allow employees to work at home forever. BuzzFeed News. Retrieved from https://www.buzzfeednews.com/article/alexkantrowitz/ twitter-will-allow-employees-to-work-at-home-forever.

Kossek, E.E., Lautsch, B.A., \& Eaton, S.C. (2006). Telecommuting, control, and boundary management: Correlates of policy use and practice, job control, and
work-family effectiveness. Journal of Vocational Behavior, 68(2), 347-367. work-family effectiveness. Journal of Voct
https://doi.org/10.1016/j.jvb.2005.07.002

Marlow, S.L., Lacerenza, C.N., \& Salas, E. (2017). Communication in virtual teams: A conceptual framework and research agenda. Human Resource Management Review, 27(4), 575-589. https://doi.org/10.1016/j.hrmr.2016.12.005

Miles, R.E., \& Snow, C.C. (1986). Organizations: New concepts for new forms. California Management Review, 28(3), 62-73. https://doi.org/10.2307/41165202

Mokhtarian, P.L. (1991). Defining telecommuting. Institute of Transportation Studies. Retrieved from https://escholarship.org/uc/item/35c4q71r.

Mokhtarian, P.L., Salomon, I., \& Choo, S. (2005). Measuring the measurable: Why can't we agree on the number of telecommuters in the U.S.? Quality and Quantity, 39(4), 423-452. https://doi.org/10.1007/s11135-004-6790-z

Morganson, V.J., Major, D.A., Oborn, K.L., Verive, J.M., \& Heelan, M.P. (2010) Comparing telework locations and traditional work arrangements: Differences in work-life balance support, job satisfaction, and inclusion. Journal of Manageria Psychology, 25(6), 578-595. https://doi.org/10.1108/02683941011056941

Mullenweg, M. (2020, March 6). Coronavirus and the remote work experiment no one asked for. Matt Mullenweg. Retrieved from https://ma.tt/2020/03/coronavirusremote-work/.

Munkvold, B.E. (1999). Challenges of IT implementation for supporting collaboration in distributed organizations. European Journal of Information Systems, 8(4), 260-272. https://doi.org/10.1057/palgrave.ejis.3000340

Nilles, J.M. (1988). Traffic reduction by telecommuting: A status review and selected bibliography. Transportation Research Part A: General, 22(4), 301-317. https:// doi.org/10.1016/0191-2607(88)90008-8

O’Neill, T.A., Hambley, L.A., \& Chatellier, G.S. (2014). Cyberslacking, engagement, and personality in distributed work environments. Computers in Human Behavior, 40, 152-160. https://doi.org/10.1016/j.chb.2014.08.005

Oliver, S., \& Kandadi, K.R. (2006). How to develop knowledge culture in organizations? A multiple case study of large distributed organizations. Journal of Knowledge Management, 10(4), 6-24. https://doi.org/10.1108/13673270610679336 
Pinsonneault, A., \& Boisvert, M. (2001). The impacts of telecommuting on organizations and individuals: A review of the literature. In N. Johnson (Ed.) Telecommuting and virtual offices: Issues and opportunities (pp. 163-185). IGI Global, PA: Hershey.

Priego-Roche, L.M., Front, A., \& Rieu, D. (2016). A framework for virtual organization requirements. Requirements Engineering, 21(4), 439-460. https://doi. org/10.1007/s00766-015-0223-5

Raghuram, S., Hill, N.S., Gibbs, J.L., \& Maruping, L.M. (2018). Virtual work: Bridging research clusters. Academy of Management Annals, 13(1), 308-341. https://doi. org/10.5465/annals.2017.0020

Rockmann, K.W., \& Pratt, M.G. (2015). Contagious offsite work and the lonely office: The unintended consequences of distributed work. Academy of Management Discoveries, 1(2), 150-164. https://doi.org/10.5465/amd. 2014.0016
Schweitzer, L., \& Duxbury, L. (2010). Conceptualizing and measuring the virtuality of teams. Information Systems Journal, 20(3), 267-295. https://doi.org/10.1111/ j.1365-2575.2009.00326.x

Spivack, A.J., \& Rubin, B.A. (2011). Spaces to control creative output of the knowledge worker: A managerial paradox? In Proceedings of the 2011 I Conference (pp. 312-318). https://doi.org/10.1145/1940761.1940804

Travica, B. (1997). The design of the virtual organization: A research model. In AMCIS 1997 Proceedings. Retrieved from https://aisel.aisnet.org/amcis1997/270.

US Office of Personnel Management. (2013). 2013 status of telework in the federal government: Report to the Congress. US Office of Personnel Management, DC: Washington.

Watson-Manheim, M.B., \& Belanger, F. (2002). Exploring communication-based work processes in virtual work environments. In Proceedings of the 35th Annual Hawaii International Conference on System Sciences (pp. 3604-3613). https://doi org/10.1109/HICSS.2002.994459 